Aging Clin. Exp. Res. 12: 417-429, 2000

\title{
Sleep disordered breathing in the elderly
}

\author{
J-P. Janssens ${ }^{1}$, S. Pautex ${ }^{1}$, H. Hilleret ${ }^{2}$, and J-P. Michel ${ }^{1}$ \\ ${ }^{1}$ Department of Geriatrics, and ${ }^{2}$ Department of Psychiatry, University Hospitals of Geneva, Geneva, \\ Switzerland
}

ABSTRACT. Sleep disordered breathing (SDB), i.e., obstructive, central or mixed sleep apneas, has been recognized as a common occurrence in the elderly. Aging is per se associated with a decrease in the quality of sleep; SDB may further disrupt the sleep architecture in older subjects. The prevalence of obstructive sleep apnea (OSA) increases with aging; available studies report prevalence rates of $11-62 \%$. Furthermore, OSA has been associated with increased mortality in older adults. Central apneas and periodic breathing occur with increased frequency either in subjects with neurological disorders such as infarction, tumor, sequelae of infection, diffuse encephalopathies, or in chronic heart failure. Patients with cerebrovascular disease (stroke, or transient ischemic attacks) have a markedly high prevalence of $S D B$, mainly OSA. In these patients, SDB is associated with a poorer functional prognosis at 3 and 12 months after the acute event, and a higher mortality. The clinical impact of SDB on cognitive function appears to be modest in patients without dementia, although there is a moderate increase in daytime sleepiness. In Alzheimer s disease (AD) however, $S D B$ occurs more frequently than in nondemented older subjects, and its severity is correlated with the degree of cognitive impairment. The hypothesis of a causal relationship between $A D$ and $S D B$ remains a subject of controversy. The possibility of $S D B$ should be considered in the elderly in the differential diagnosis of "reversible dementias", increased daytime sleepiness, or unexplained right-sided heart failure.

(Aging Clin. Exp. Res. 12: 417-429, 2000)

${ }^{\circ} 2000$, Editrice Kurtis

\section{INTRODUCTION}

In $1996,14.2 \%$ of the Swiss population was over 65 years of age; according to WHO estimates, this proportion is expected to reach $20 \%$ by the year 2020 (1). Aging is associated with an increasing frequency of dissatisfaction with the quality of sleep; indeed, one half of subjects aged over 65 and living at home, and two thirds of those residing in longterm facilities suffer from sleep disorders (2).

The etiological diagnosis of sleep disorders may be difficult in the elderly; somatic disorders such as heart disease, stroke, Parkinson's disease, chronic pain, chronic pulmonary diseases, nocturnal polyuria, and psychiatric diseases such as depression and dementia - which are more prevalent in the elderly - may all have a negative impact on the quality of sleep. Furthermore, "normal" aging appears to be associated with changes in the quality of sleep such as decreased slow-wave sleep, increased fragmentation of sleep, more frequent arousals and night-time wakefulness (3).

Among the secondary causes of sleep disruption, "sleep disordered breathing" (SDB) has been increasingly recognized as a common occurrence in the elderly (4-6). The concept of SDB encompasses disturbances of the breathing pattern occurring only or primarily during sleep such as obstructive sleep apnea or hypopnea, central or mixed apnea syndromes, periodic breathing and nocturnal hypoventilation (7). Although a significant proportion of elderly subjects have SDB, controversy exists regarding its clinical significance in older subjects, i.e., its relationship to cognitive impairment and to increased morbidity or mortality (8). The diagnosis of SDB is often delayed in elderly subjects because of: 1) atypical clinical

Key words: Cerebrovascular disease, dementia, elderly, sleep apnea, sleep disordered breathing.

Correspondence: J.P. Janssens, M.D., Hôpital de Gériatrie, Route de Mon Idée, 1226, Thônex, Geneva, Switzerland. E-mail: jansen@cmu.unige.ch

Received March 13, 2000; accepted in revised form August 22, 2000. 
presentations; 2) the frequency of sleep-related complaints in this age group considered - by the patient and the physician - as inherent to normal aging; and 3) the difficulty in performing polygraphic or polysomnographic recordings in older patients with cognitive impairment.

This review describes the age-associated physiological changes in sleep architecture and breathing during sleep, and analyzes the clinical relevance of $\mathrm{SDB}$, and its occurrence in frequent medical conditions associated with aging such as congestive heart failure, cerebrovascular disease, and dementia. We will not discuss the modifications in breathing pattern associated with chronic lung disorders, or obesity (i.e., nocturnal alveolar hypoventilation), as well as other causes of sleep disruption such as periodic leg movements.

\section{PHYSIOLOGICAL CHANGES IN BREATHING DURING SLEEP}

Sleep architecture

Two distinctive electroencephalographic (EEG) sleep states have been defined: rapid eye movement sleep or paradoxical sleep (REM), and non-rapid eye movement sleep (NREM). NREM sleep is subdivided into four stages of progressively deepening sleep (IIV). Normal sleep comprises a recurring pattern of sequential stages (NREM, then REM sleep) with a periodicity of 60-100 minutes; the 2 or 3 first cycles encompass NREM stages III and IV, the last cycles are of shorter duration, and do not usually comprise slow- wave sleep.

\section{Breathing and ventilatory control during sleep}

Sleep onset is associated with a reduction in reticular activating system (RAS) activity, which is thought to be responsible for the fall in respiratory drive noted during sleep (9). During stages I and II (about $60 \%$ of total sleeping time), total ventilation $\left(V_{\mathrm{E}}\right)$ decreases slightly: this change is a consequence of a fall in tidal volume $\left(\mathrm{V}_{\mathrm{t}}\right)$, but breathing frequency (FR) remains unchanged; periodic breathing (gradual waxing and waning of $V_{t}$ over $30-60$ second cycles) occurs physiologically during NREM stages I and II, with central apneas lasting less than 15 seconds, and increases in frequency with aging. During stages III and IV (approximately 20\% of total sleeping time), also referred to as slow-wave sleep because of the characteristic EEG pattern, $V_{E}$ further declines (-15\% compared to wakefulness), mainly through a decrease also in $\mathrm{V}_{\mathrm{t}}$; this causes a physiological increase in arterial partial pressure of carbon dioxide $\left(\mathrm{PaCO}_{2}\right)$ of 3-7 mmHg $(0.4-0.9$
$\mathrm{kPa})$, and a decrease in arterial partial pressure of oxygen $\left(\mathrm{PaO}_{2}\right)$ of 3.5 to $9.4 \mathrm{mmHg}(0.5-1.3 \mathrm{kPa})$, i.e., an approximate $2 \%$ fall in oxygen saturation $\left(\mathrm{SaO}_{2}\right)$; the pattern of breathing is regular, apneas are rare (2).

With the onset of NREM sleep, upper airway resistance approximately doubles because of a decrease in peripheral muscular tone, and a loss of EMG activity affecting dilator muscles of the upper airways.

During REM sleep (20\% of total sleeping time), the pattern of breathing is irregular, with variations in both $\mathrm{V}_{\mathrm{t}}$ and $\mathrm{FR}$; paradoxical chest movements may be noted; central apneas lasting less than 15 seconds are frequent. Peripheral muscle tone is abolished; this is also the case with the muscles that control upper airway patency, thus increasing the likelihood of upper airway obstruction during REM sleep (9). $V_{E}$ is decreased as in slow-wave sleep.

\section{AGE-RELATED CHANGES IN SLEEP ARCHITECTURE, BREATHING AND VENTILATORY CONTROL}

\section{Sleep architecture}

Objective studies of sleep architecture demonstrate increased sleep fragmentation, and decreased sleep quality in the elderly (Fig. 1). Characteristic age-associated EEG changes $(2,10)$ such as a decrease in the amplitude of slow waves (stages III and IV, restorative

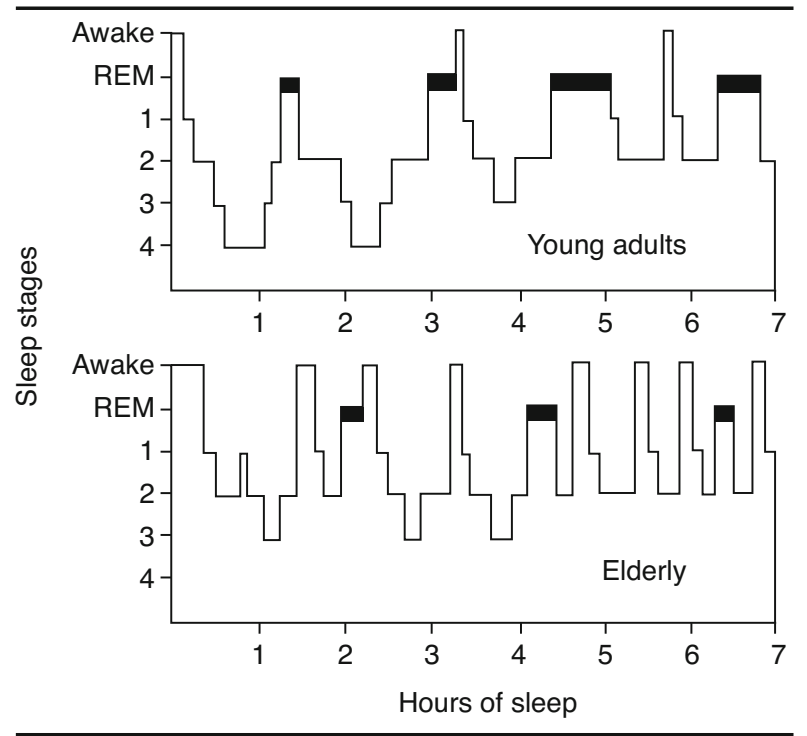

Figure 1 - Changes in sleep architecture associated with aging: decrease in NREM stages III and IV, increased sleep fragmentation and number of arousals. Adapted from: Kales A., Kales J., N. Engl. J. Med. 290: 487-499, 1974. 
Table 1 - Age-related changes in sleep architecture.

\begin{tabular}{ll}
\hline Time in bed (TIB) & Increased \\
Total sleep time (TST) & Unchanged if nap included \\
Sleep efficiency (TST/TIB) & Decreased \\
Sleep fragmentation & Increased \\
NREM Stage I & Small increase \\
NREM Stage II & Increased due to decrease in slow-wave sleep \\
NREM Stages III and IV & Decreased \\
REM sleep & No change in \% of TST
\end{tabular}

Adapted from Burger et al. (2).

component of sleep), a reduction in the total amount of slow-wave sleep, and an increase in the number of changes in sleep stages, are summarized in Table 1. These changes appear to be related to age-related neuronal loss, and disturbances of circadian oscillators (2). Aging is also associated with a reduction in sleep efficiency (i.e., the ratio of time spent in bed to time spent asleep), and an increased frequency of daytime napping.

\section{Breathing and ventilatory control}

Aging is associated with a marked attenuation in the heart rate and ventilatory responses to hypoxia and hypercapnia (11-13). Indeed, Kronenberg et al. compared the responses to hypercapnia and hypoxia of healthy young men (aged 22-30) to those of older men (aged 64-73); in the older group, the ventilatory response to hypercapnia was decreased by $60 \%$, and the response to hypoxia by $75 \%$, compared to the younger subjects. These observations suggest that there is an age-related decline in the ability to integrate information received from sensors (peripheral and central chemoreceptors, mecanoreceptors), and generate appropriate neural activity.

The hypoxic ventilatory response is reduced during sleep; it decreases more during NREM sleep, than during REM sleep (2). Noteworthy is the fact that sleep deprivation further diminishes the nocturnal ventilatory responses to hypoxia and hypercapnia (14). Arousal from sleep is preserved during hypercapnia, but markedly impaired during hypoxia. This impaired ventilatory response may prolong the duration of apneas or hypopneas, and result in more severe oxygen desaturations in elderly subjects, especially during REM sleep.

Aging is also associated with a diminished perception of added resistive loads, such as that generated by upper airway collapse (15-17). Furthermore, when compared to younger adults, older subjects generate a decreased inspiratory effort during ob- structive sleep apnea (18).

\section{OBSTRUCTIVE SLEEP APNEA SYNDROME (OSA)}

\section{Pathophysiology and clinical consequences}

OSA refers to repetitive episodes of upper airway obstruction occurring during sleep. Cessation of airflow for at least 10 seconds (apnea) or a $50 \%$ reduction in airflow for at least 10 seconds (hypopnea) occur despite continuing respiratory effort (i.e., persistent thoracic and/or abdominal movements on polysomnographic recordings) (Fig. 2). Upper airway obstruction is a consequence of the hypotonic muscular tone of the dilator muscles of the pharynx which increases the collapsibility of the upper airway, and the negative airway pressure generated by the inspiratory muscles. The gravitational effects of the supine posture usually adopted for sleep tend to further promote the upper airway obstruction (posterior movement of the tongue). Apneas cause blood oxygen desaturation. Repeated arousals occur because of increasing respiratory effort $(14,19)$, and to a lesser degree, hypoxia, leading to increased fragmentation of sleep (20).

The principal symptoms of OSA (daytime sleepiness, and slight to moderate neuropsychological impairment) result from the repeated arousals required to re-establish sufficient muscular tone in the pharynx to reopen the upper airways, and the decrease in stages 3 and 4 and in REM sleep (21).

Snoring, obesity and male sex are major risk factors for OSA $(3,22)$. Upper airway morphology (pharyngeal cross-section, size of the mandible) is also a major contributive factor $(23,24)$. The recurrent hypoxemic episodes that characterize OSA, particularly if associated with COPD and/or daytime hypoxemia, may lead to both pulmonary and systemic hypertension, cardiac arrhythmias, and possibly decreased survival (25).

\section{Epidemiology}

The wide variability in the reported prevalence of 
Flow

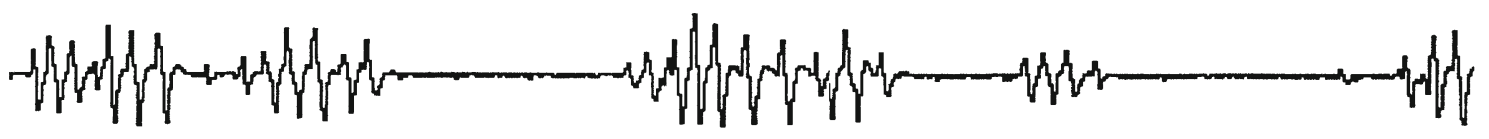

Chest

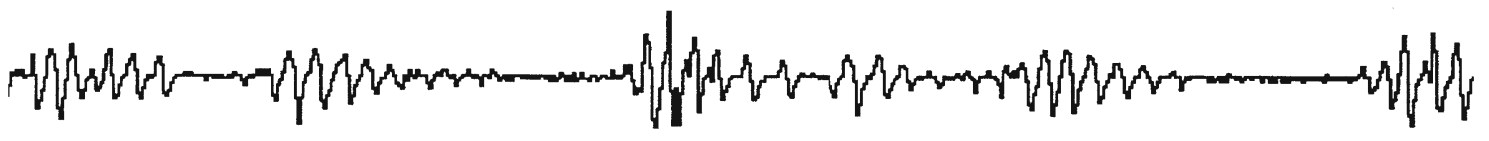

Abdomen

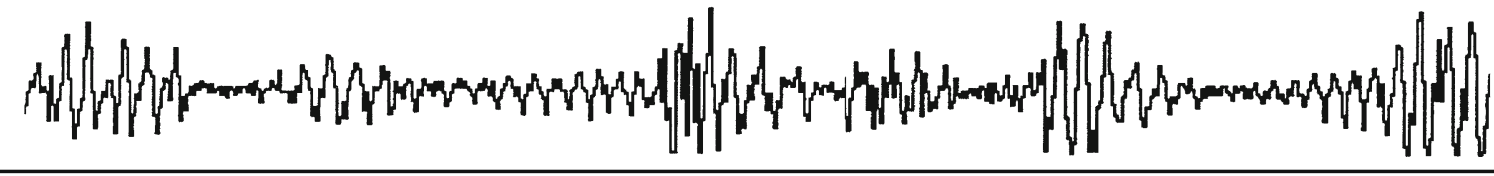

Figure 2 - Polysomnographic recording in a 66-year-old male subject; only airflow, chest movements and abdominal movements are shown. Upper tracing shows airflow (and airflow cessation: apneas); "chest effort" and "abdominal effort" tracings show persistent respiratory efforts during apneas. The segment shown represents 5 minutes of recording.

OSA results from the use of different criteria for defining and quantifying respiratory events. Indeed, different thresholds for normal us pathological sleep have been used in prevalence studies: an apnea index (AI) of 5-15/h, or an apnea-hypopnea index (AHI) of 5-20/h (also labelled RDI: respiratory disturbance index) (26).

In younger adult populations (i.e., aged under 60), the prevalence of OSA $(\mathrm{AHI}>15 / \mathrm{h})$ is currently estimated to be $4 \%$ in women and $9 \%$ in men (27). The prevalence increases in post-menopausal vs premenopausal women.

A large prevalence study based on a questionnaire survey of 1389 subjects aged $65 \pm 3$ years reported that $49.5 \%$ of participating subjects were snorers, and $10.8 \%$ suffered from nocturnal apneic episodes (28). However, few prevalence studies, based on either polysomnography or polygraphy, include more than 50 subjects. Hoch et al. (Table 2A) studied 105 healthy elderly subjects aged 60-91 years by polysomnography: $13.3 \%$ had an $\mathrm{AHI} \geq 10 / \mathrm{h}$, and $6.8 \%$ had an $\mathrm{AI} \geq 10$; the median $\mathrm{AHI}$ increased signifi- cantly across decades from age 60 to age 90 years, and the prevalence of SDB clearly increased with aging; $69 \%$ of all events were central apneas, $22 \%$ were obstructive apneas; $8 \%$ were mixed events (6). The largest prevalence studies were published by Ancoli-Israël et al. (4). Her largest study includes data from a random sample of 427 elderly community-dwelling persons in the San Diego area (Table 2B) studied by polygraphy (thoracic and abdominal Respitrace ${ }^{\circledR}$ bands, peripheral EMG, and wrist activity); in this study, the prevalence of an $\mathrm{Al} \geq 5$ was $24 \%$, and that of an $\mathrm{AHI} \geq 10$ was $62 \%$. In subjects with an $\mathrm{Al} \geq 5,59 \%$ of all respiratory events were obstructive apneas, 30\% were central apneas, and $10 \%$ were mixed apneas. Ancoli-Israël et al. also studied 200 patients from a nursing home (mean age: $81.9 \pm 8.6$ ); $41 \%$ of all patients had an $\mathrm{AI} \geq 5 / \mathrm{h}$, and $11 \%$ had an $\mathrm{Al} \geq 10 / \mathrm{h}$ (percentage of obstructive apneas not specified) (29). Another study by Hoch et al. including 56 healthy elderly individuals aged $69 \pm 5$ years found lower prevalence rates; $5.3 \%$ had an $\mathrm{Al} \geq 5$, and $3.6 \%$ an $\mathrm{AI} \geq 10$, all respiratory events

Table 2A - Prevalence of sleep disordered breathing per age group.

\begin{tabular}{|c|c|c|c|c|}
\hline Age & $60-69$ & $70-79$ & $80-89$ & All \\
\hline No. & 34 & 33 & 38 & 105 \\
\hline Age (mean $\pm S D)$ & $65.1(2.7)$ & $73.0(2.9)$ & $83.5(3.0)$ & NA \\
\hline \multicolumn{5}{|l|}{ No. of subjects (\%): } \\
\hline $\mathrm{AHI} \geq 5$ & $1(2.9)$ & $11(33.3)$ & $15(39.5)$ & $27(25.7)$ \\
\hline $\mathrm{AHI} \geq 10$ & $1(2.9)$ & $5(15.1)$ & $8(21.1)$ & $14(13.3)$ \\
\hline $\mathrm{AI} \geq 5$ & $0(0)$ & $4(12.1)$ & 7 (18.9) & $11(10.7)$ \\
\hline $\mathrm{AI} \geq 10$ & $0(0)$ & $2(6.1)$ & $5(13.5)$ & $7(6.8)$ \\
\hline
\end{tabular}

Data from Hoch C.C. et al. (6). NA: not available; AI: apnea index; AHI: apnea-hypopnea index. 
Table 2B - Prevalence of sleep disordered breathing per age group.

\begin{tabular}{|c|c|c|c|c|}
\hline No. of subjects & 166 & 201 & 53 & $\begin{array}{c}\text { All } \\
420\end{array}$ \\
\hline Age $($ mean $\pm S D)$ & & & & $72.4(6.4)$ \\
\hline Age groups: range & $65-69$ & $70-79$ & $80-89$ & 65-99 \\
\hline \multicolumn{5}{|c|}{ No. of subjects (\%) with: } \\
\hline $\mathrm{AI} \geq 5$ & $43(26)$ & $43(21)$ & $14(26)$ & $100(24)$ \\
\hline $\mathrm{Al} \geq 10$ & $20(12)$ & $13(6)$ & $10(19)$ & $43(11)$ \\
\hline $\mathrm{AI} \geq 20$ & $6(4)$ & $6(3)$ & $4(8)$ & $16(4)$ \\
\hline No. of subjects & 152 & 181 & 52 & 385 \\
\hline Age groups: range & $65-69$ & $70-79$ & $80-89$ & $65-99$ \\
\hline \multicolumn{5}{|c|}{ No. of subjects (\%) with: } \\
\hline $\mathrm{AHI} \geq 10$ & $93(61)$ & $113(62)$ & $34(65)$ & $240(62)$ \\
\hline $\mathrm{AHI} \geq 20$ & $66(43)$ & 77 (43) & $27(52)$ & $170(44)$ \\
\hline $\mathrm{AHI} \geq 40$ & $37(24)$ & $38(21)$ & $17(33)$ & $92(24)$ \\
\hline
\end{tabular}

Data from S. Ancoli-Israël et al. (4).

being equally divided between central, obstructive and mixed apneas (30).

Noteworthy is the frequent occurrence of OSA in patients with chronic obstructive pulmonary disease (COPD). Indeed, COPD is highly prevalent in elderly patients, and OSA occurs in 10 to $15 \%$ of COPD patients (31). The coexistence of OSA and COPD defines the "overlap syndrome". Patients with the "overlap syndrome" tend to have a lower baseline $\mathrm{SaO}_{2}$ and a higher $\mathrm{PaCO}_{2}$ than patients with OSA alone; they are also at higher risk of developing episodes of profound hypoxemia during sleep than nonCOPD patients; they are therefore particularly prone to suffer from the complications of chronic hypoxemia such as cor pulmonale, pulmonary hypertension, and polycythemia $(31,32)$.

In summary, snoring, a known risk factor for OSA, is highly prevalent in subjects aged $>65$; the prevalence of pathological $\mathrm{AI}$ and $\mathrm{AHI}$ increases significantly with aging, 30 to $60 \%$ of the respiratory events being obstructive apneas. The possibility of an "overlap syndrome" should be considered in elderly COPD patients with an increased body-mass index (32).

\section{Mortality and OSA in the elderly}

Several publications have shown that OSA is associated with an increased risk for mortality (33). In a cohort study of 198 non-institutionalized elderly individuals aged $67 \pm 8$ years, Bliwise et al. showed that an $\mathrm{AHI}>10 / \mathrm{h}$ was associated with an increased hazard of cardiovascular death (34). In 233 elderly subjects living in nursing homes, Ancoli-Israël et al. also noted that patients with OSA had a greater tendency to die in their sleep, and that there was a strong association between $\mathrm{AHI}$ and mortality in women (35).

The impact of OSA on neuropsychological function will be discussed under the subheading "SDB and cognitive impairment".

Treatment of OSA in the elderly

Treatment of OSA includes modification of behavioral factors (such as weight loss, avoidance of alcohol, smoking, and sedative or hypnotic drugs), nasal continuous positive pressure (nCPAP), mandibular advancement devices, and surgical procedures.

Weight loss, in obese patients with OSA, may significantly decrease the number of apneic events, and sleep disruption, and increase nocturnal $\mathrm{SaO}_{2}$.

Thyroid replacement therapy is mandatory in patients with hypothyroidism, which should be sought for in all documented cases of SDB.

Use of hypnotics and psychotropic agents should be discouraged in patients with OSA, because of the risk of increasing the frequency and length of apneas and hypopneas. Protriptyline is the only psychotropic agent which has a minor impact on OSA; protriptyline decreases REM-associated OSA, but has no documented effect on OSA occurring during NREM sleep; in selected patients with mainly REMassociated OSA, protriptyline may improve sleep oxygenation, and decrease sleepiness (36).

Continuous Positive Airway Pressure via a nasal mask ( $n C P A P)$, the most widely used treatment for OSA, has been shown to improve nocturnal oxygen saturation, quality of sleep, and quality of life, in younger adults. To date, there are no studies of the use and impact of long-term nCPAP in elderly subjects. Interestingly however, nCPAP is widely used in older subjects; in Switzerland, 14\% of all nasal CPAP devices were used by patients aged over 65 years (37); in France, approximately 20\% of the 13900 


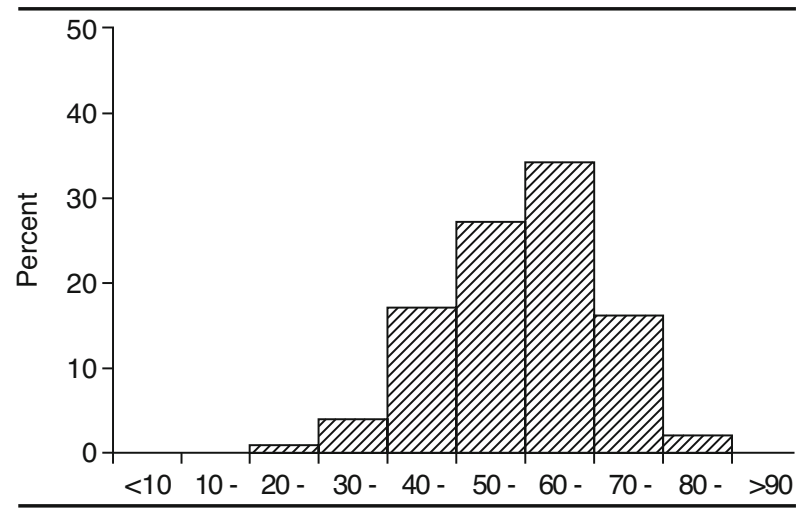

Figure 3 - Data from the 1996 ANTADIR observatory; frequency of prescription of home nCPAP per age group ( $N=13900$ patients).

subjects under home nCPAP therapy in 1996 and followed by ANTADIR (National association for the domiciliary treatment of patients with respiratory insufficiency) were aged 70 and over (Fig. 3). Longterm acceptance of positive pressure ventilation via nasal mask has been documented in patients aged 75 and over, suggesting that its use is feasible in this age group, although the issue of nCPAP in the elderly has not been specifically addressed (38). Acceptance of nCPAP is, however, low in patients who suffer from few OSA-related symptoms, or who suffer from cognitive impairment, both being frequent occurrences in the elderly.

Patients with the "overlap syndrome" and daytime $\mathrm{PaO}_{2}$ above $60 \mathrm{mmHg}$ should be treated as patients with OSA, i.e., with nocturnal nCPAP or, in patients with associated hypoventilation and hypercapnia, non-invasive positive pressure ventilation (NIPPV). Nocturnal oxygen therapy alone in patients with an "overlap syndrome" carries the risk of increasing nocturnal $\mathrm{PaCO}_{2}$, and has not been shown to improve OSA-associated daytime symptoms, quality of sleep or prognosis (39).

Mandibular advancement devices are considered as second-line therapy, for patients who do not tolerate nCPAP. Many different devices are available, but one major limitation is that appliances need to be fixed on the patients teeth, and cannot be used in patients with dentures (19).

Several surgical procedures are available for the treatment of OSA: surgical or laser-assisted uvulopalatopharyngoplasty (UPPP); inferior mandibular osteotomy and genioglossal advancement with hyoid myotomy and suspension (MOHM), or maxillo-mandibular advancement osteotomy (MMO) (40, 41). However, available data concerning either UPPP,
$\mathrm{MOHM}$, or MMO refer essentially to patients in the 40 to 55 years of age group (41). Surgical options are rarely considered in elderly subjects for several reasons: 1) The frequent occurrence of comorbidities in older subjects increases the risk of surgical procedures and general anesthesia. 2) The impact of UPPP or MOHM is unknown in older patients, and modest in younger adults; indeed, the success rate of UPPP [defined as a post-operative decrease in the respiratory disturbance index (sum of $\mathrm{AI}$ and $\mathrm{AHI}$ ) of at least $50 \%$ and a post-operative value below $20 / \mathrm{h}$ ] is $52 \%$ in carefully selected patients, and drops to less than $20 \%$ in patients with combined retropalatal and retrolingual obstruction, or retrolingual obstruction alone (41). MOHM has a success rate of up to $60 \%$ when performed by experienced surgeons in specialized centers in younger adults; no data are available, however, for the old and very old. 3) Advanced age per se is considered as a contra-indication for MMO in a comprehensive review on surgical management of OSA by Powell et al. (40).

\section{CENTRAL APNEA}

Central apnea (CA) episodes are associated with complete cessation of respiratory effort. It has been suggested that CA occurs at 4 to $10 \%$ of the rate of OSA (42). Patients with CA can be subdivided into 2 groups: those with a depressed central drive, and those with a normal or increased respiratory (or chemical) drive.

The first group comprises subjects with lesions to the brainstem such as sequelae of infections, infarction, and tumor (bilateral posterolateral medullary lesions); the clinical syndrome mimics "Ondine's curse", i.e., failure of automatic respiration with occurrence of predominantly nocturnal central hypoventilation. This has also been described in encephalitis, cervical cordotomy, bulbar poliomyelitis, the Shy-Dragger syndrome, multiple sclerosis, and after radiation necrosis. A decline in central drive with occurrence of CA can also be seen in certain neuromyopathies such as amyotrophic lateral sclerosis, myotonic dystrophy, muscular dystrophy, and myasthenia gravis (43).

The second group comprises subjects with a preserved or increased respiratory (chemical) drive. CA occurs physiologically in subjects breathing at high altitude, where chronic hyperventilation causes $\mathrm{Pa}-$ $\mathrm{CO}_{2}$ to be low, and drop below the apneic threshold, leading to periodic breathing. The same mechanisms are implicated in the association between chronic heart failure and periodic breathing (Cheyne-Stoke respiration). 
Flow

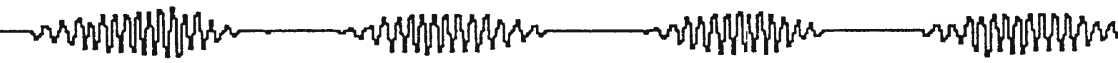

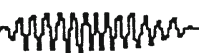

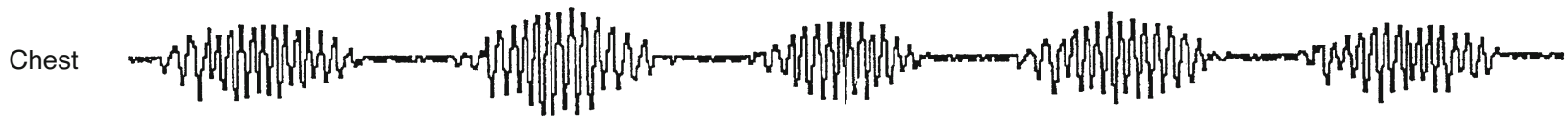

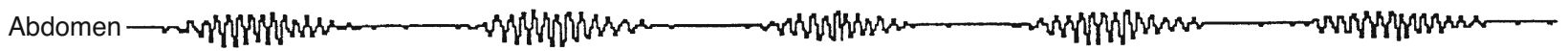

Figure 4 - Polysomnographic recording in a 71-year-old male subject, suffering from severe cardiomyopathy; only airflow, chest movements and abdominal movements are shown. Airflow tracing shows Cheyne-Stokes breathing; "chest effort" and "abdominal effort" tracings show disappearance of respiratory efforts during apneas (central apneas).

In the elderly, $\mathrm{CA}$ is most often associated with cardiovascular or cerebrovascular diseases; it also occurs as a consequence of diffuse encephalopathies, or severe metabolic disorders (hepatic or renal failure). Noteworthy is the interaction between CA and obstructive apnea; the majority of patients with CA also have obstructive events, i.e., mixed apneas (4, 6); upper airway collapse may occur at the nadir of periodic breathing, when the drive to the inspiratory muscles and upper airway muscles is minimal, inducing obstructive apnea. Furthermore, the occurrence of obstructive apneas tends to increase the instability of the respiratory control system (i.e., prolonged apneas, increased compensatory hyperventilation).

\section{SDB AND CONGESTIVE HEART FAILURE (CHF): CHEYNE-STOKES BREATHING}

Pathophysiology and clinical presentation

Periodic, or Cheyne-Stokes breathing (CSB), occurs in patients with severe heart failure; this abnormal breathing pattern, characterized by alternating periods of hyperpnea and hypopnea or apnea, is a form of central apnea, and is much more common during sleep than wakefulness (Fig. 4). The putative mechanism of CSB is related to an increased sensitivity of the respiratory centers to carbon dioxide $\left(\mathrm{CO}_{2}\right)$ (44-47). As previously noted, during sleep, total $\mathrm{V}_{\mathrm{E}}$ decreases, and $\mathrm{PaCO}_{2}$ rises by 3-7 mmHg. If during sleep $\mathrm{PaCO}_{2}$ drops below a certain level, referred to as the apneic threshold, ventilation ceases (central $\mathrm{a} \quad \mathrm{p} \quad \mathrm{n} \quad \mathrm{a}$ ) a $\mathrm{n} d$ $\mathrm{PaCO}_{2}$ is restored to its previous level. In persons with increased sensitivity to $\mathrm{CO}_{2}$, the negative feedback system that controls breathing elicits a large ventilatory response when $\mathrm{PaCO}_{2}$ rises ("increased controller gain"); by driving $\mathrm{PaCO}_{2}$ below the apneic threshold, the consequent hyperventilation results in central apnea. This can explain recurring cycles of central apnea and hyperventilation during sleep. The presence of hypoxemia can further increase the slope of the ventilatory response to hypercapnia. Furthermore, patients with CSB have a significantly lower diurnal $\mathrm{PaCO}_{2}$ and transcutaneous nocturnal $\mathrm{CO}_{2}$ $\left(\mathrm{PtcCO}_{2}\right)$ than subjects without CSB, probably as a consequence of interstitial edema, and stimulation of pulmonary irritant and juxtacapillary stretch receptors: as such, smaller variations in $\mathrm{V}_{\mathrm{E}}$ can bring $\mathrm{Pa}-$ $\mathrm{CO}_{2}$ below the apneic threshold, and induce periodic breathing (47). Indeed, the finding of a low diurnal $\mathrm{PaCO}_{2}$ in patients with heart failure is highly predictive of $\mathrm{CSB}$. The contribution of a prolonged circulation time is probably not a key factor in the genesis of CSB, although it is important in determining the length of the cycles in CSB $(44,45)$.

CSB causes considerable disruption of sleep architecture, with a markedly increased number of arousals and sleep stage changes, and may mimic the clinical picture of OSA (Fig. 5) (48). Patients with CSB have an increase in stages I and II of NREM sleep, and a decrease in slow-wave sleep $(47,48)$. Many patients with CSB present symptoms of disturbed sleep; polysomnographic recordings show that apneic episodes are frequently followed by arousals, and patients also suffer from paroxysmal nocturnal dyspnea, difficulty in initiating sleep, or insomnia. CSB has also been noted to induce acute confusion (delirium) (49).

Figures 4 and 5 show the typical ventilatory pattern of CSB during polysomnography in a patient with chronic left ventricular dysfunction (cardiomyopathy), and the alterations in sleep architecture associated with CSB.

\section{Treatment of CSB}

Treatment is based on optimal management of $\mathrm{CHF}$, the use of theophylline and acetazolamide (as 


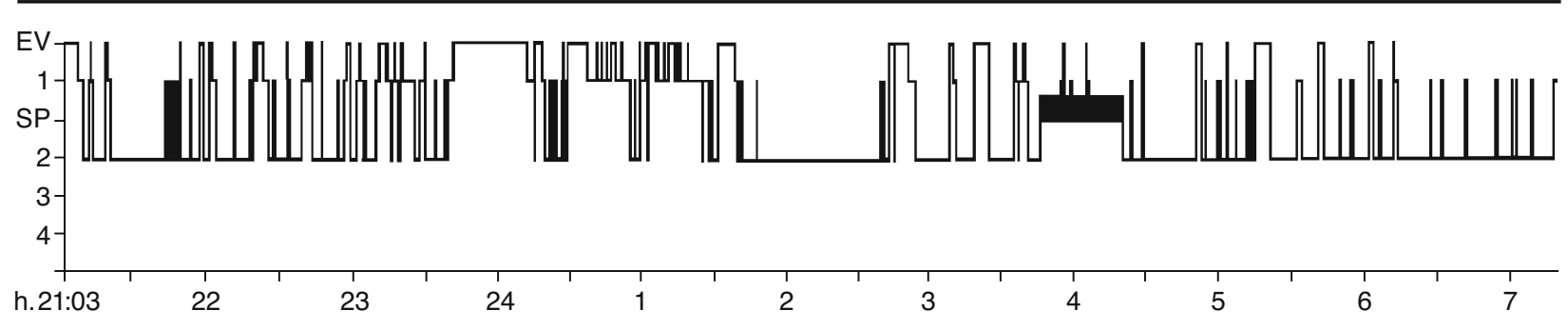

Figure 5 - Polysomnographic recording in a 71-year-old male subject, suffering from severe cardiomyopathy. Hypnogram shows severe disruption of sleep architecture because of Cheyne-Stokes breathing, with multiple arousals and disappearance of NREM stages III and IV. The Figure shown covers recording over one night.

stimulants for the respiratory centers) (36), nasal nCPAP (at pressures of +5 to $+10 \mathrm{~cm} \mathrm{H}_{2} \mathrm{O}$, to decrease ventricular afterload by decreasing transmural ventricular pressure), and rarely, nocturnal respiratory assistance with bi-level positive airway pressure (BiPAP) (47). A bi-level barometric ventilator specifically designed for the treatment of CSB has been recently commercialized, and is undergoing clinical evaluation (ResMed Autoset $\mathrm{CS}^{\circledR}$ ). Figure 6 shows the effect of nCPAP on transmural ventricular pressure for a given systolic blood pressure, explaining the positive effect of nCPAP on afterload of the left ventricule.

\section{SDB AND CEREBROVASCULAR DISEASE}

Recent studies suggest a high prevalence of SDB (predominantly OSA) associated with either transient ischemic attacks (TIA), or stroke (50-53). Bassetti et al. studied by polysomnography 39 subjects (mean age: 57 years) within 10 days of a first episode of acute stroke; OSA with an AHI $>10$ was found in 14 subjects (36\%), Cheynes-Stokes in $4(10 \%)$, and mixed SDB in 7 (18\%). Prevalence of SDB was similar in those with supratentorial and infratentorial stroke (52). In another controlled study of patients after TIA or stroke, 36 patients underwent polysomnography within 12 days after the acute event; 25 subjects (69\%) had an AHI $\geq 10$, with a similar proportion in patients with TIA or stroke (51). In a study of 47 patients with recent ischemic stroke, based on overnight pulse oximetry, an increase in desaturation index (DI: number of drops in $\mathrm{SaO}_{2} / \mathrm{h}$ exceeding $4 \%$ ) was associated with a poorer functional status at 3 and 12 months after the acute event, and with a higher 1-year mortality; polysomnography of a subgroup of 19 patients suggested that SDB was mainly caused by OSA (50).

In summary, patients having suffered from either TIA or a recent stroke have a high incidence of $\mathrm{SDB}$, mainly caused by OSA; SDB is associated with a worse prognosis in these patients. The causal relationship between OSA and cerebrovascular disease (CVD) is not settled to date; the increased prevalence

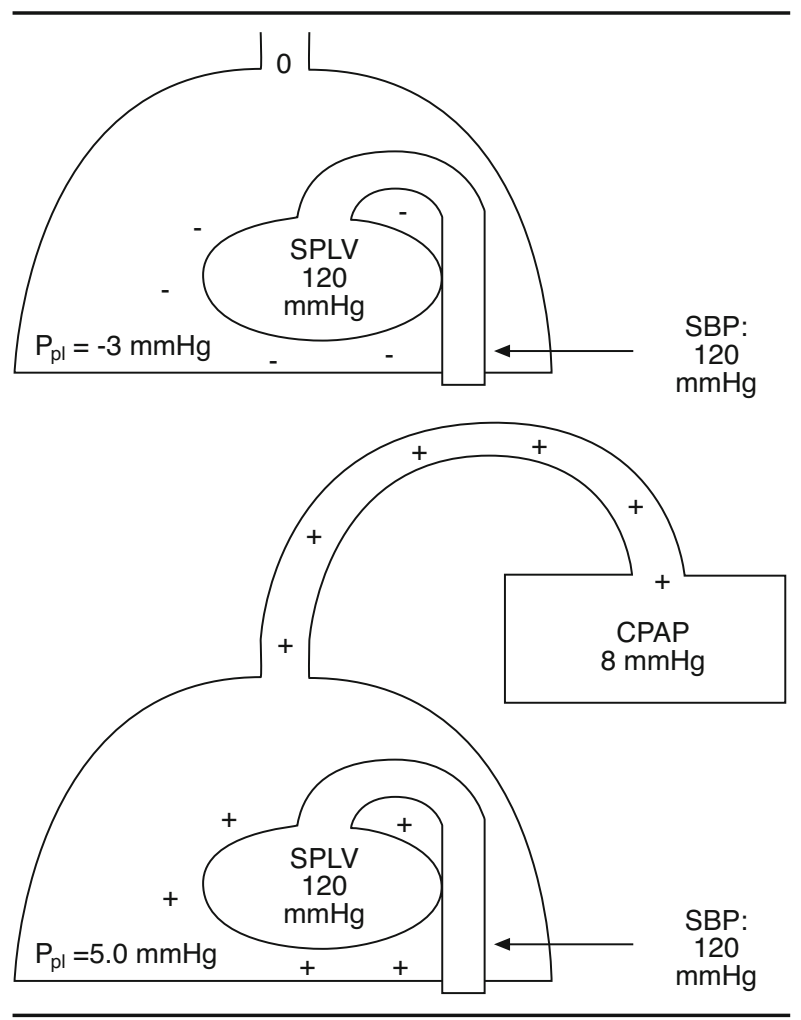

Figure 6 - Use of nCPAP in Cheyne-Stokes breathing associated with left ventricular failure. Upper Figure shows negative intrapleural pressure $\left(P_{p l}\right)$ without $n C P A P$; transmural ventricular pressure, for a systolic blood pressure (SBP) of $120 \mathrm{mmHg}$, is $120-(-3)=123 \mathrm{mmHg}$. Lower Figure shows the effect of 8 $\mathrm{mmHg}$ of $n C P A P$; intrapleural pressure $\left(P_{p l}\right)$ is now $+5.0 \mathrm{~mm}$ $\mathrm{Hg}$; transmural ventricular pressure, for the same SBP, is 120 - $5=115 \mathrm{mmHg}$, which illustrates the decreased afterload for the left ventricle as a consequence of $n C P A P$. SPLV: systolic pressure in left ventricle. Adapted from Escourrou et al. (45). 
of OSA in patients with CVD may be a cause or a consequence of the acute cerebral events. Unfortunately, treatment by nCPAP in these patients is frequently poorly tolerated, and to date no study of its impact on the outcome of patients with OSA and a history of either TIA or a recent stroke is available.

\section{SDB AND COGNITIVE IMPAIRMENT}

Chronic hypoxia has been associated with moderate to severe neuropsychological impairment. Grant et al. (54) studied 203 patients with COPD aged $64 \pm 8$ years from the Nocturnal Oxygen Therapy Trial (NOTT), with a mean daytime $\mathrm{PaO}_{2}$ of 51 $\mathrm{mmHg}$ : $77 \%$ of these patients were found to have a neuropsychologic deficit; in $42 \%$, these deficits were moderate to severe in magnitude, a rate triple that of a control group of older subjects without COPD; higher cognitive functions (abstracting ability, complex perceptual-motor integration) were most severely affected; this had also been noted by Krop et al. (55). Findley et al. (56) studied younger subjects with OSA, and found that cognitive impairment associated with OSA was correlated with mean $\mathrm{SaO}_{2}$ during sleep and awake $\mathrm{PaO}_{2}$. Interestingly, despite these findings, the relationship between SDB and cognitive function in older subjects is unclear. Knight et al. studied 27 subjects aged $76 \pm 6$ years; 10 had sleep apnea (mean AI: 17/h), 17 had no sleep apnea; although there was a modest increase in daytime sleep tendency, no significant differences between the 2 groups were found for any of the cognitive tests, and no correlations were noted between neuropsychologic performance and sleep parameters (57). Phillips et al. studied 92 subjects aged $64 \pm 8$ years by polysomno-graphy; no correlations were found between either neuropsychological testing, or daytime sleepiness, and indices of SDB (8). Similarly, Berry et al. performed polysomnography on 28 healthy elderly subjects aged $70 \pm 6$ years (mean AHI: 4.9 \pm 7.6, mean DI: $29 \pm 42 / \mathrm{h}$ ), and found no correlation between SDB indices and daytime functioning or neuropsychologic testing (58). According to Hoch et al., the severity of SDB did not correlate with daytime sleepiness, medical burden, or severity of depressive symptoms (Hamilton depression scale) (59).

Conversely, Yesavage et al. (60) performed polysomnography and neuropsychological tests in 41 non-demented male subjects aged $69.5 \pm 6.5$ years, and showed that 5 of the 11 tests performed - testing memory and comprehension - were correlated

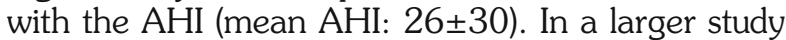
of 427 community-dwelling elderly subjects, AncoliIsraël et al. also found a correlation between SDB indices and nocturnal wandering or confusion, day- time sleepiness, and depression (4). More recently, Gottlieb et al. reported data on 1824 subjects aged $65 \pm 11$ years, with a mean $\mathrm{AHI}$ of $11 \pm 15 / \mathrm{h}$ : a significant progressive increase in sleepiness (Epworth Sleepiness Scale: ESS) was noted with increasing $\mathrm{AHI}$; this relationship was not influenced by age or gender (61).

In summary, the clinical impact of SDB on cognitive function and neuropsychologic testing appears to be modest in elderly patients without dementia; data based on large population studies, however, show an increase in daytime sleepiness with increasing SDB indices in older adults.

\section{SLEEP DISORDERS AND ALZHEIMER S DISEASE}

The prevalence of dementia is about $1 \%$ at the age of 60 years, and doubles every five years, to reach 30 to $50 \%$ by the age of 85 . Alzheimer's disease (AD) accounts for approximately $70 \%$ of all cases of dementia (62). Several authors have noted a higher prevalence of SDB in patients with $A D$ when compared to control groups. Furthermore, anecdotal early reports of dementia-like symptoms (memory impairment, concentration difficulties, confusion) associated with sleep apnea (63) led to the speculation that there could be a causal relationship between $\mathrm{SDB}$ and $\mathrm{AD}$ : in $\mathrm{AD}$, sleep apnea could be a consequence of cell loss in the brainstem respiratory centers; conversely, neuronal degeneration in $\mathrm{AD}$ could be hastened by the nightly insult of intermittent cerebral hypoxemia related to SDB.

Specific changes in sleep architecture have been described in AD: a reduced sleep efficiency, an increased proportion of stage I, a decreased proportion of slow-wave sleep and REM sleep, and an increased number of awakenings (64).

Hoch et al. compared the prevalence of SDB in patients with $\mathrm{AD}(\mathrm{N}=34)$ vs three groups: healthy controls $(\mathrm{N}=56)$; patients with depression $(\mathrm{N}=35)$; and patients with dementia and depression $(\mathrm{N}=24)$. A significantly greater proportion of patients with $\mathrm{AD}$ had an $\mathrm{AI} \geq 10 / \mathrm{h}$ (29\%) when compared to controls $(3.6 \%)$, or patients with depression $(8 \%)$; the predominant type of apnea was obstructive (30). Similar findings were reported by Reynolds et al. (65) in a controlled study; $43 \%$ of patients with $\mathrm{AD}$ $(\mathrm{N}=21$, aged $70 \pm 8$ years) had an $\mathrm{AI} \geq 5$ vs $4.3 \%$ of controls ( $\mathrm{N}=23$, aged $69 \pm 6$ ). Ancoli-Israël et al. (66) studied 235 elderly institutionalized patients (152 women aged $83.5 \pm 8.5$ years, and 83 men aged $79.7 \pm 7.5$ years) by polygraphy (thoracic and abdominal Respitrace ${ }^{\circledR}$ bands, peripheral EMG, and 


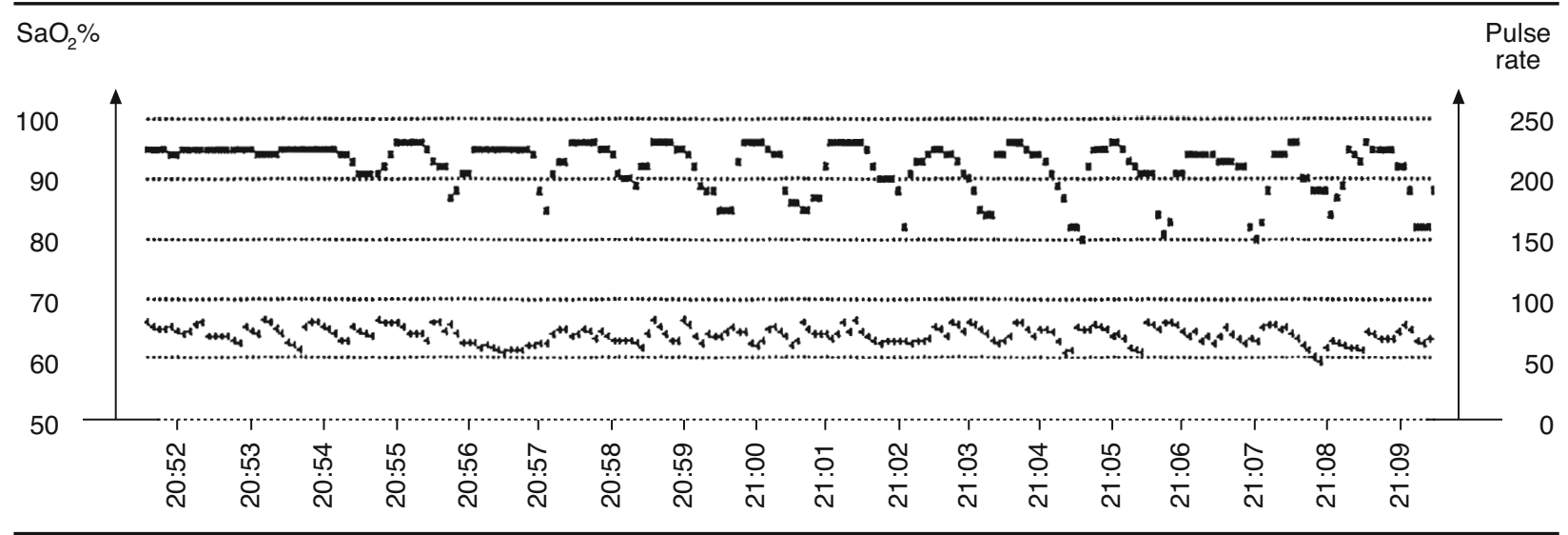

Figure 7 - Pulse-oximetry tracing of a 75-year-old male subject with OSA. Upper tracing shows oxygen saturation (SaO $)_{2}$; lower tracing shows heart rate. Characteristic asymmetrical desaturations are shown, with $\mathrm{SaO}_{2}$ fluctuating between 80 and $95 \%$. Recording made with Minolta Pulsox 7 oximeter, room air.

wrist activity): $43 \%$ of the patients had an $\mathrm{AI} \geq 5$; 138 patients had dementia based on a Mattis Dementia Rating Scale (DRS); the mean AHI was significantly higher in patients with severe dementia than in patients with mild-to-moderate or no dementia; there were significant correlations between $\mathrm{AHI}$ and the DRS scores for attention, initiation and perseveration, construction, conceptualization and memory. Two studies, however, failed to detect any significant difference between patients with vs without $\mathrm{AD}$ as to mean $\mathrm{AHI}(67,68)$. Interestingly, patients who desaturated overnight were more likely to be confused in the morning, suggesting a possible interaction between $\mathrm{AD}$ and SDB (67). Using a static charge-sensitive bed, one study (69) compared the prevalence of SDB in patients with multi-infarct dementia (MID), AD, and healthy controls: patients with MID and AD had a higher mean AHI, and a higher prevalence of subjects with an $\mathrm{AHI} \geq 10$ than controls; also, the prevalence of subjects with an $\mathrm{AHI} \geq 10$ tended to increase with the severity of the dementia. Little is known about dementia and apnea in the severely ill, because of the difficulty in performing sleep studies in a sleep laboratory in this group of patients.

Unfortunately, mean nocturnal $\mathrm{SaO}_{2}$, DI, and minimal $\mathrm{SaO}_{2}$ are seldom reported.

In summary, SDB has been more frequently studied in $\mathrm{AD}$ than in MID; available data suggest that $\mathrm{SDB}$ occurs more frequently, and is more severe in patients with $\mathrm{AD}$ (or MID) than in elderly controls; whether $\mathrm{SDB}$ is frequent in $\mathrm{AD}$ because both diseases are highly prevalent in this age group or because there is a causal relation between both diseases remains a subject of speculation.

\section{DIAGNOSING SDB IN AN ELDERLY POPULATION}

The gold standard for the diagnosis of SDB is polysomnography (PSG), i.e., the simultaneous recording of EEG, eye movements, electromyography, airflow, pulse oximetry, electrocardiogram, and chest and abdominal movements by inductance plethysmography. However, PSG has several major drawbacks, such as availability, cost, and the difficulty in performing it in even moderately demented patients. Furthermore, a considerable night-to-night variability has been noted in the elderly, with a clear "first night effect" on the pattern of sleep, although changes are less significant for SDB indices; the use of low cut-off values for the diagnosis of $\mathrm{SDB}$ (i.e., $\mathrm{AHI} \geq 5$ ) may change the clinical classification of patients from night to night $(70,71)$.

The simplest diagnostic tool for SDB is nocturnal pulse-oximetry (Fig. 7). In selected groups of younger adults (snorers, obese patients, or patients with complaints suggestive of OSA), nocturnal pulse-oximetry is moderately sensitive and specific (although patients with predominantly hypopneas are poorly detected). Values of sensitivity (Se) and specificity (Sp) vary considerably, however, according to the thresholds used to define SDB (72). Chiner et al. reported on the variations in $\mathrm{Se}$ and $\mathrm{Sp}$ according to different threshold values for ODI (oxygen desaturation index: number of drops in $\mathrm{SaO}_{2} / \mathrm{h}$ exceeding $4 \%$ ) in outpatients with symptoms suggestive of OSA, defining $\mathrm{SDB}$ as $\mathrm{AHI} \geq 15$ : for an $\mathrm{ODI} \geq 5$, Se was $82 \%$ and $\mathrm{Sp}$ 
$76 \%$; for an $\mathrm{ODI} \geq 10$, Se and $\mathrm{Sp}$ were respectively 71 and $90 \%$; for an $\mathrm{ODI} \geq 15$, Se was $62 \%$ and $\mathrm{Sp}$ $93 \%$ (73). However, the diagnostic value of nocturnal pulse-oximetry in the elderly is unknown: groups at high risk for OSA are more difficult to identify in older subjects because of the paucity or lack of specificity of symptoms; specificity will most probably drop because of the frequency of CA and CSB in the elderly; to date, no study has approached the validity of nocturnal pulse-oximetry - or that of algorythms combining clinical data and nocturnal pulse-oximetry - in the elderly. The same is true for polygraphy; to be clinically contributive in older subjects, a polygraphic recording must offer the possibility of differentiating CA or CSB from OSA, which requires inductance plethysmography to analyze chest and abdominal respiratory movements, simultaneously with respiratory flow. The latest version of the ResMed Autoset ${ }^{\circledR}$ offers such a possibility, with a graphic re$\mathrm{p} O \mathrm{r} \mathrm{t} \quad \mathrm{o} \mathrm{f} \quad \mathrm{r} e$ spiratory effort, but has not been studied to our knowledge in a group of older patients.

When using nocturnal pulse-oximetry, it is important to know whether the subject studied slept or not, and during which parts of the recording; Ancoli-Israël et al. studied the use of a wrist-activity monitor, and showed that it had a sensitivity of $87 \%$ and a specificity of $90 \%$ in differentiating sleep from wakefulness (74). Another option to be explored is the use of continuous video recording, synchronized with the timer of the oximeter.

An interesting technique for detecting SDB in older subjects is the static charge-sensitive bed (SCSB), used by Erkinjuntti et al. (69) in patients with $\mathrm{AD}$ and MID. The SCSB consists of a thin mattress, sensitive to respiratory and body movements; recording does not require any electrodes or cables connected to the patient, and thus a more physiological sleep situation is achieved; coupling with pulse-oximetry allows the distinction between OSA and periodic breathing (CSB) (75). In a comparative study of 77 patients studied simultaneously by polysomnography and SCSB coupled with oximetry, Se was $100 \%$ and Sp was $67 \%$ for the detection of OSA (76).

\section{CONCLUSIONS}

Sleep disordered breathing occurs with increasing frequency in elderly subjects, either as predominantly central apnea (i.e., Cheyne-Stokes or periodic breathing), or obstructive sleep apnea. Both entities cause important changes in the quality of sleep, with a markedly increased number of arousals and changes in sleep stages, and a decrease in slow-wave sleep
- the restorative component of sleep. The clinical symptoms may be subtle, but in non-demented subjects SDB is associated with an increase in daytime sleepiness, and a variable intensity of neuropsychological dysfunction. In patients with dementia (Alzheimer's disease or multi-infarct disease), SDB probably occurs even more frequently, and may have a negative impact on cognitive performances.

The finding of SDB is associated with a poorer prognosis in older patients; this is clearly documented in patients with cerebrovascular disease or severe heart failure. Because OSA and CSB are potentially reversible disorders, SDB should be considered in the differential diagnosis of "reversible dementias", increased daytime sleepiness, or unexplained rightsided heart failure in the elderly.

\section{REFERENCES}

1. WHO: The World Health Report 1996. WHO, Geneva, 1996, p.137.

2. Burger C., Shepard J.: Sleep-disordered breathing and aging. In: Mahler D. (Ed.), Pulmonary disease in the patient. Marcel Dekker Inc., New York, Basel, Hong Kong, 1993, pp. 61-80.

3. Prinz P., Vitiello M., Raskind M., Thorpy M.: Geriatrics: sleep disorders and aging. N. Engl. J. Med. 323: 520-526, 1990

4. Ancoli-Israël S., Kripke D., Klauber M., Mason W., Fell R., Kaplan O.: Sleep-disordered breathing in community-dwelling elderly. Sleep 14: 486-495, 1991.

5. Fleury B.: Sleep apnea syndrome in the elderly. Sleep 15: S39-S41, 1992.

6. Hoch C., Reynolds C., Monk T., Buysse D., Yeager A., Houck P., Kupfer D.: Comparison of sleep-disordered breathing among healthy elderly in the seventh, eighth, and ninth decades of life. Sleep 13: 502-511, 1990.

7. Feinsilver S., Hertz G.: Sleep in the elderly patient. Clin. Chest Med. 14: 405-411, 1993.

8. Phillips B., Berry D., Schmitt F., Magan L., Gerhardstein D., Cook Y.: Sleep-disordered breathing in the healthy elderly: clinically significant? Chest 101: 345-349, 1992.

9. Calverley P.: Impact of sleep on respiration. In: McNicholas W. (Ed.), Respiratory disorders during sleep. ERS Journals, Sheffield, UK, 1998, pp. 9-27.

10. Dement W., Miles L., Carskadon M.: "White paper" on sleep and aging. J. Am. Geriatr. Soc. 30: 25-50, 1982.

11. Peterson D., Pack A., Silage D., Fishman A.: Effects of aging on ventilatory and occlusion pressure responses to hypoxia and hypercapnia. Am. Rev. Respir. Dis. 124: 387-391, 1981.

12. Kronenberg R., Drage G.: Attenuation of the ventilatory and heart rate responses to hypoxia and hypercapnia with aging in normal man. J. Clin. Invest. 52: 1812-1819, 1973.

13. Brischetto M., Millman D., Peterson D., Silage D., Pack A.: Effect of aging on ventilatory response to exercise and $\mathrm{CO} 2$. J. Appl. Physiol. 56: 1143-1150, 1984. 
14. Grassino A., Begin P.: Rôle des muscles respiratoires dans l'interruption de l'apnée obstructive du sommeil (Role of inspiratory muscles in the interruption of obstructive apnea during sleep). Rev. Mal. Respir. 7: 403-410, 1990.

15. Tack M., Altose M., Cherniack N.: Effects of ageing on respiratory sensation produced by elastic loads. J. Appl. Physiol. 50: 844-850, 1981.

16. Tack M., Altose M., Cherniack N.: Effect of aging on the perception of resistive ventilatory loads. Am. Rev. Respir. Dis. 126: 463-467, 1982.

17. Manning H., Mahler D., Harver A.: Dyspnea in the elderly. In: Mahler D.A. (Ed.), Pulmonary disease in the elderly patient. Marcel Dekker Inc., New-York, 1993, pp. 81-111.

18. Krieger J., Sforza E., Boudewijns A., Zamagni M., Petiau C. Respiratory effort during obstructive sleep apnea: role of age and sleep state. Chest 112: 875-883, 1997.

19. Strollo P., Rogers R.: Obstructive sleep apnea. N. Engl. J. Med. 334: 99-104, 1996

20. Launois S., Whitelaw W.: Voies aériennes supérieures et troubles respiratoires au cours du sommeil (Upper airways and sleep-disordered breathing). Rev. Mal. Respir. 7: 391402, 1990.

21. Remmers J., deGroot W., Sauerland E., Anch A.: Pathogenesis of upper airway occlusion during sleep. J. Appl. Physiol. 44: 931-938, 1978.

22. Bliwise D., Feldman D., Bliwise N., Carskadon M., Kraemer H., North C., Petta D., Seidel W., Dement W.: Risk factors for sleep disordered breathing in heterogenous geriatric populations. J. Am. Geriatr. Soc. 35: 132-141, 1987.

23. Bradley T., Brown I., Grossman R., Zamel N., Martinez D., Phillipson E., Hoffstein V.: Pharyngeal size in snorers, nonsnorers and patients with obstructive sleep apnea. N. Engl. J. Med. 315: 1327-1331, 1986.

24. Rivlin J., Hoffstein V., Kalbfleisch J., McNicholas W., Zamel N., Bryan A.: Upper airway morphology in patients with idiopathic obstructive sleep apnea. Am. Rev. Respir. Dis. 129: 355-360, 1984

25. Weitzenblum E., Krieger J., Apprill M., Vallée E., Ehrhart M., Ratomaharo J., Oswald M., Kurtz D.: Daytime pulmonary hypertension in patients with obstructive sleep apnea syndrome. Am. Rev. Respir. Dis. 138: 345-349, 1988.

26. Strading J.: Obstructive sleep apnoea: definitions, epidemiology, and natural history. Thorax 50: 683-689, 1995.

27. Young T., Palta M., Dempsey J., Skatrud J., Weber S., Badr S.: The occurrence of sleep-disordered breathing among middle-aged adults. N. Engl. J. Med. 328: 1230-1235, 1993.

28. Dealberto M., Pajot N., Courbon D., Alperovitch A.: Breathing disorders during sleep and cognitive performance in an older community sample: the EVA study. J. Am. Geriatr. Soc. 44: 1287-1294, 1996.

29. Ancoli-Israël S., Parker L., Sinaee R., Fell R., Kripke D.: Sleep fragmentation in patients from a nursing home. $J$. Gerontol. 44: 18-21, 1989.

30. Hoch C., Reynolds C., Kupfer D., Houck P., Berman S., Stack J.: Sleep-disordered breathing in normal and pathological aging. J. Clin. Psychiatry 47: 499-503, 1986.

31. McNicholas W.T.: Impact of sleep in respiratory failure. Eur. Respir. J. 10: 920-933, 1997.

32. Chaouat A., Weitzenblum E., Krieger J., Ifoundza T., Oswald M., Kessler R.: Association of chronic obstructive pulmonary disease and sleep apnea syndrome. Am. J. Respir. Crit. Care Med. 151: 82-86, 1995.

33. He J., Kryger M., Zorick F., Conway W., Roth T.: Mortality and apnea index in obstructive sleep apnea. Experience in 385 male patients. Chest 94: 9-14, 1988.

34. Bliwise D., Bliwise N., Partinen M., Pursley A., Dement W.: Sleep apnea and mortality in an aged cohort. Am. J. Public Health 78: 544-547, 1988.

35. Ancoli-Israël S., Klauber M., Kripke D., Parker L., Cobarrubias M.: Sleep apnea in female patients in a nursing home. Increased risk of mortality. Chest 96: 1054-1058, 1989.

36. Hudgel D., Thanakitcharu S.: Pharmacological treatment of sleep-disordered breathing. Am. J. Respir. Crit. Care Med. 158: 691-699, 1998.

37. Künzli N., Grize L.: Sauerstoff-Langzeittherapie, Schlafapnoe-Behandlung und Heimventilation: Lungenligen Schweiz 1989-1996. Publication de la Ligue Pulmonaire Suisse, 1997.

38. Janssens J., Cicotti E., Fitting J., Rochat T.: Non-invasive home ventilation in patients over 75 years of age: tolerance, compliance, and impact on quality of life. Respir. Med. 92: 1311-1320, 1998

39. Fletcher E., Munafo D.: Role of nocturnal oxygen therapy in obstructive sleep apnea. When should it be used? Chest 98: 1497-1504, 1990

40. Powell N., Riley R., Robinson A.: Surgical management of obstructive sleep apnea syndrome. Clin. Chest Med. 19: 77-86, 1998.

41. Sher A., Kenneth B., Schechtman B., Piccirillo J.: The efficacy of surgical modifications of the upper airway in adults with obstructive sleep apnea syndrome. Sleep 19: 156-177, 1996

42. De Backer W.: Central sleep apnoea. In: McNicholas W. (Ed.), Respiratory disorders during sleep. European Respiratory Society Journals, Sheffield, UK, 1998, pp. 266-284.

43. Guilleminault C., Stoohs R., Quera-Salva M-A.: Sleep-related obstructive and nonobstructive apneas and neurologic disorders. Neurology 42: S53-S60, 1992.

44. Javaheri S., Parker T., Wexler L., Michaels S., Stanberry E., Nishyama H., Roselle G.: Occult sleep-disordered breathing in stable congestive heart failure. Ann. Intern. Med. 122: 487-492, 1995.

45. Escourrou P., Pellerin D., Nedelcoux H.: Insuffisance cardiaque et troubles respiratoires du sommeil (Heart failure and sleepdisordered breathing). Rev. Mal. Respir. 16: 161-171, 1999.

46. Wilcox I., McNamara S., Dodd M., Sullivan C.: Ventilatory control in patients with sleep apnoea and left ventricular dysfunction: comparison of obstructive and central apnoea. Eur. Respir. J. 11: 7-13, 1998.

47. Quaranta A., D'Alonzo G., Krachman S.: Cheyne-Stokes respiration during sleep in congestive heart failure. Chest 111: 467-473, 1997.

48. Dowdell W., Javaheri S., McGinnis W.: Cheyne-Stokes respiration presenting as sleep apnea syndrome: clinical and polysomnographic features. Am. Rev. Respir. Dis. 141: 871879, 1990.

49. Rasche K., Orth M., Schultze-Werninghaus G.: Unklarer Verwirrtheitszustand im alter als folge eines zentralen Schlafapnoesyndroms - eine kasuistik (Unexplained confusion in the aged as a sequela of sleep apnea syndrome - a case report). Pneumologie 47: S738-S740, 1993. 
50. Good D., Henkle J., Gelber D., Welsh J., Verhulst S.: Sleepdisordered breathing and poor functional outcome after stroke. Stroke 27: 252-259, 1996.

51. Bassetti C., Aldrich M., Chervin R., Quint D.: Sleep apnea in patients with transient ischemic attack and stroke: a prospective study of 59 patients. Neurology 47: 1167-1173, 1996.

52. Bassetti C., Aldrich M., Quint D.: Sleep-disordered breathing in patients with acute supra- and infratentorial strokes. A prospective study of 39 patients. Stroke 28: 1765-1772, 1997.

53. Dyken M., Somers V., Yamada T., Ren Z., Zimmerman M.: Investigating the relationship between stroke and obstructive sleep apnea. Stroke 27: 401-407, 1996.

54. Grant I., Heaton R.K., McSweeny J., Adams K.M., Timms R.M.: Neuropsychologic findings in hypoxemic chronic obstructive pulmonary disease. Arch. Intern. Med. 142: 14701476, 1982

55. Krop H.D., Block A.J., Cohen E.: Neuropsychologic effects of continuous oxygen therapy in chronic obstructive pulmonary disease. Chest 64: 317-322, 1973.

56. Findley L., Barth J., Powers D., Wilhoit S., Boyd D., Suratt P.: Cognitive impairment in patients with obstructive sleep apnea and associated hypoxemia. Chest 90: 686-690, 1986.

57. Knight H., Millman R., Gur R., Saykin A., Doherty J., Pack A.: Clinical significance of sleep apnea in the elderly. Am. Rev. Respir. Dis. 136: 845-850, 1987.

58. Berry D., Phillips B., Cook Y., Schmitt F., Honeycutt N., Edwards C., Lamb D., Magan L., Allen R.: Sleep-disordered breathing in healthy aged persons: one year follow-up and daytime sequelae. Sleep 12: 211-215, 1989.

59. Hoch C., Reynolds C., Buysse D., Machen M., Schlernitzauer M., Hall F., Kupfer D.: Sleep-disordered breathing in healthy and spousally bereaved elderly: a one-year follow-up study. Neurobiol. Aging 13: 741-746, 1992.

60. Yesavage J., Bliwise D., Guilleminault C., Carskadon M., Dement W.: Preliminary communication: intellectual deficit and sleep-related respiratory disturbance in the elderly. Sleep 8: 30-33, 1985.

61. Gottlieb D., Whitney C., Bonekat W., Iber C., James G., Leb- owitz M., Javier Neto F., Rosenberg C.: Relation of sleepiness to respiratory disturbance index: the sleep heart health study. Am. J. Respir. Crit. Care Med. 159: 502-507, 1999.

62. Geldmacher D., Whitehouse P.: Evaluation of dementia. N. Engl. J. Med. 335: 330-336, 1996.

63. Schletens P., Visscher F., Van Keimpema A., Lindeboom J., Taphoorn M., Wolters E.: Sleep apnea syndrome presenting with cognitive impairment. Neurology 41: 155-156, 1991.

64. Monjan A.: Sleep and dementia: measurement issues. Alzhe imer Dis. Assoc. Disord. 8: S223-S226, 1994.

65. Reynolds C., Kupfer D., Taska L., Hoch C., Sewitch D., Restifo K., Spiker D., Zimmer B., Marin R., Nelson J., Martin D., Morycz R.: Sleep apnea in Alzheimer's dementia: correlation with mental deterioration. J. Clin. Psychiatry 46: 257-261, 1985.

66. Ancoli-Israël S., Klauber M., Butters N., Parker L., Kripke D.: Dementia in institutionalized elderly: relation to sleep apnea. J. Am. Geriatr. Soc. 39: 258-263, 1991.

67. Bliwise D., Yesavage J., Tinklenberg J., Dement W.: Sleep apnea in Alzheimer's disease. Neurobiol. Aging 10: 343346, 1989.

68. Smallwood R., Vitiello M., Giblin E., Prinz P.: Sleep apnea: relationship to age, sex, and Alzheimer's dementia. Sleep 6: 16-22, 1983.

69. Erkinjuntti T., Partinen M., Sulkava R., Telakivi T., Salmi T., Tilvis R.: Sleep apnea in multiinfarct dementia and Alzheimer's disease. Sleep 10: 419-425, 1987.

70. Aber W., Block A., Hellard D., Webb W.: Consistency of respiratory measurements from night to night during the sleep of elderly men. Chest 96: 747-751, 1989.

71. Mosko S., Dickel M., Ashurst J.: Night to night variability in sleep apnea and sleep-related periodic leg movements in the elderly. Sleep 11: 340-348, 1988.

72. Ryan P., Hilton M., Boldy D., Evans A., Bradbury S., Sapiano S., Prowse K., Cayton R.: Validation of British Thoracic Society guidelines for the diagnosis of the sleep apnoea/hypopnoea syndrome: can polysomnography be avoided? Thorax 50: 972-975, 1995.

73. Chiner E., Signes-Costa J., Arriero J.M., Marco J., Fuentes I., Sergado A.: Nocturnal oximetry for the diagnosis of the sleep apnoea/hypopnoea syndrome: a method to reduce the number of polysomnographies? Thorax 54: 968-971, 1999.

74. Ancoli-Israël S., Clopton P., Klauber M., Fell R., Mason W.: Use of wrist activity for monitoring sleep/wake in demented nursing-home patients. Sleep 20: 24-27, 1997.

75. Salmi T., Partinen M., Hyyppä M., Kronholm E.: Automatic analysis of static charge sensitive bed (SCSB) recordings in the evaluation of sleep-related apneas. Acta Neurol. Scand. 74: 360-364, 1986.

76. Svanborg E., Larsson H., Carlsson-Nordlander B., Pirskanen R.: A limited diagnostic investigation for obstructive sleep apnea syndrome: oximetry and static charge sensitive bed. Chest 98: 1341-1345, 1990. 